\title{
A AVALIAÇÃO NA CONSTRUÇÃO DA APRENDIZAGEM NA ESCOLA MUNICIPAL SÃO FRANCISCO EM SERRA DO RAMALHO, BAHIA
}

\author{
Ma. Maria Roseane dos Santos Duarte \\ E-mail: mariaroseaneduarte@gmail.com \\ Dr. Márcio Wendel Santana Coêlho \\ E-mail: mwdoctormaster@gmail.coml
}

\begin{abstract}
RESUMO
O presente artigo é resultado do recorte da pesquisa de mestrado apresentada a Facultad Interamericana de Ciencias Sociales - FICS, no Mestrado em Ciências da Educação. A pesquisa teve por finalidade analisar os diferentes conceitos de avaliação e seus pressupostos, tendo como tema de pesquisa " $A$ Avaliação na construção da aprendizagem na escola São Francisco em Serra do Ramalho, Bahia”. Como metodologia optou-se por uma pesquisa de caráter exploratório por uma abordagem qualitativa. Para o desenvolvimento desse estudo, o método utilizado foi o Materialismo Histórico Dialético - MHD e os instrumentos de coleta de dados foram através de questionários com quatro (04) docentes, cinco (05) alunos e análise documental (Projeto Político Pedagógico - PPP). Sob esta ótica, foi fundamental perceber que a avaliação ocorre no decorrer de todo processo ensino aprendizagem na unidade escolar investigada. Esses aspectos contemplados, contribuíram para um maior conhecimento sobre a teoria e a prática no processo de avaliação, permitindo um convívio mais próximo com as ideias dos diferentes autores abordados no decorrer da pesquisa. Percebeu-se também que várias dificuldades precisam ser vencidas como a resistência à participação dos pais e demais representantes da comunidade escolar, a falta de politização e o comodismo. Nesse sentido, as práticas pedagógicas desenvolvidas na Escola São Francisco, conceitua para uma educação de qualidade e a democratização no sistema de ensino.
\end{abstract}

Palavras-chave: Avaliação; Gestão democrática; Projeto Político Pedagógico

\begin{abstract}
This article is the result of an excerpt from the master's research presented to the Facultad Interamericana de Ciencias Sociales - FICS, in the Master's Degree in Educational Sciences. The research aimed to analyze the different concepts of assessment and their assumptions, having as research theme "Assessment in the construction of learning in the São Francisco school in Serra do Ramalho, Bahia". As a methodology, exploratory research with a qualitative approach was chosen. For the development of this study, the method used was Dialectical Historical Materialism - MHD and the data collection instruments were through questionnaires with four (04) teachers, five (05) students and documental analysis (Political Pedagogical Project - PPP). From this perspective, it was essential to realize that the assessment occurs throughout the entire teaching-learning process in the investigated school unit. These contemplated aspects contributed to a greater knowledge of theory and practice in the assessment process, allowing for closer contact with the ideas of the different authors approached during the research. It was also noticed that several difficulties need to be overcome, such as resistance to the participation of parents and other representatives of the school community, lack of politicization and self-indulgence. In this sense, the pedagogical practices developed at Escola São Francisco, conceptualizes for quality education and democratization in the education system.
\end{abstract}

Key words: Assessment; Democratic management; Political Pedagogical Project

\section{RESUMEN}

Este artículo es el resultado de un extracto de la investigación de maestría presentada a la Facultad Interamericana de Ciencias Sociales - FICS, en la Maestría en Ciencias de la Educación. La investigación tuvo como objetivo analizar los diferentes conceptos de evaluación y sus supuestos, 
teniendo como tema de investigación "Evaluación en la construcción del aprendizaje en la escuela São Francisco en Serra do Ramalho - Bahía". Como metodología se eligió una investigación exploratoria con enfoque cualitativo. Para el desarrollo de este estudio, el método utilizado fue Materialismo Histórico Dialéctico - MHD y los instrumentos de recolección de datos fueron a través de cuestionarios con cuatro (04) docentes, cinco (05) estudiantes y análisis documental (Proyecto Político Pedagógico PPP). Desde esta perspectiva, fue fundamental darse cuenta de que la evaluación se da a lo largo de todo el proceso de enseñanza-aprendizaje en la unidad escolar investigada. Estos aspectos contemplados contribuyeron a un mayor conocimiento de la teoría y la práctica en el proceso de evaluación, permitiendo un contacto más cercano con las ideas de los diferentes autores abordados durante la investigación. También se observó que es necesario superar varias dificultades, como la resistencia a la participación de los padres y otros representantes de la comunidad escolar, la falta de politización y la autocomplacencia. En este sentido, las prácticas pedagógicas desarrolladas en la Escola São Francisco, conceptualizan la educación de calidad y la democratización del sistema educativo.

Palabras clave: Evaluación; Gestión democrática; Proyecto Político Pedagógico

\section{Introdução}

A educação no Brasil perpassa na contemporaneidade, por significativas transformações e mudanças, as preocupações para aqueles que buscam por um ensino de qualidade aumentam. Essa afirmativa se pauta quando nos depararmos com os indicadores resultantes da aplicabilidade de avaliações externas e internas, que versam que os saberes ministrados pelo professorado não conseguem dirimir no alunado todas as competências e habilidades necessárias para o exercício da cidadania.

Nesse sentido, toda avaliação da aprendizagem se configura diferentemente ao longo dos tempos entre mudanças e permanências de mitos que historicamente foram construídos e tiveram sua origem na primeira modernidade com o nascimento da própria instituição escolar. Rompe-se com as tradições medievais de educação e a escola moderna se organiza, assim como também as prisões, quartéis e hospitais. Segundo Foucault (2009), o nascimento da escola não tem romantismo, pois ela nasce de jogos de poder.

Segundo Kraemer (2006), avaliação vem do latim, e significa valor ou mérito ao objeto em pesquisa, junção do ato de avaliar ao de medir os conhecimentos adquiridos pelo indivíduo. É um instrumento valioso e indispensável no sistema escolar, podendo descrever os conhecimentos, atitudes ou aptidões que os alunos apropriaram. Sendo assim a avaliação revela os objetivos de ensino já atingidos num determinado ponto de percurso e também as dificuldades no processo de ensino aprendizagem.

Partindo dessa primazia, o interesse pela temática em questão, ocorreu quando comecei a lecionar na Escola São Francisco, na qual discute rotineiramente as práticas pedagógicas e as formas de avaliar no campo da educação, sabendo que a avaliação faz parte da atividade escolar do docente e precisa ser vista como um componente importante para o processo formativo do 
aluno, possibilitando uma reflexão constante das habilidades e dificuldades, bem como do papel do docente para as transformações na sociedade.

Nesse sentido, a pesquisa apresentou como objetivo geral, analisar a avaliação na construção da aprendizagem do docente no Ensino Fundamental II da Escola Municipal São Francisco, e se está contribuindo para a aprendizagem do aluno. Como objetivos específicos, ela se dispõe a: 1) Conhecer qual a visão pedagógica que o Professor do Ensino Fundamental II da Escola Municipal São Francisco tem sobre como avaliar; 2) Identificar se a avaliação aplicada pelo Professor do Ensino Fundamental II da Escola Municipal São Francisco contribui para a aprendizagem do aluno; 3) Observar como a Escola Municipal São Francisco vem trabalhando com os professores o processo de Avaliação como ferramenta na construção da aprendizagem.

\section{Procedimentos metodológicos da pesquisa}

$\mathrm{Na}$ busca pela compreensão sobre as práticas pedagógicas e avaliativas na Escola Municipal São Francisco, que está situada no município de Serra do Ramalho, Identidade do Território Velho Chico, na Bahia, fomos em busca de uma abordagem teórico metodológica que nos permitisse uma aproximação adequada à esta realidade. Para isso, optamos pelo Materialismo Histórico Dialético (MHD), pois entendemos que uma revolução social que subvertesse a ordem vigente de poder da classe dominante sobre a classe dominada.

Nesse sentido, a característica fundamental do entendimento do materialismo histórico que é a mudança e a transformação social, de modo que o proletariado possa acessar o poder e estabelecer um governo de uniformidade social, (pelo movimento do pensamento) as leis fundamentais que definem a forma organizativa dos homens em sociedade através da história (KOSIK, 1976).

Para compreender as adaptações e desafios atuais, optamos por priorizar, neste trabalho, pela perspectiva dos docentes, ou seja, como os professores compreendem esta realidade. Assim, após tramitação e aprovação em Comitê de Ética em Pesquisa. Para isso, os professores foram procurados pelos pesquisadores, que explicaram os propósitos e métodos da pesquisa, tendo sido destacado que a participação seria livre e voluntária.

Para a coleta de dados, optamos pela utilização de um questionário, composto de perguntas fechadas, relacionadas aos objetos da pesquisa. Segundo Marconi e Lakatos (1999, p.100), "o questionário de perguntas fechadas é um instrumento composto de um conjunto de perguntas ordenadas de acordo com um critério predeterminado, que tem por objetivo coletar dados de um grupo de respondentes". Este por sua vez, objetiva levantar opiniões, crenças, sentimentos, interesses, expectativas e situações vivenciadas e, a linguagem utilizada nesse 
instrumento deve ser simples e direta para que o questionado possa compreender e responder com clareza o que está sendo perguntado.

Para Gil (1999, p.128), afirma que o questionário pode ser definido,

Como a técnica de investigação composta por um número mais ou menos elevado de questões apresentadas por escrito às pessoas, tendo por objetivo o conhecimento de opiniões, crenças, sentimentos, interesses, expectativas, situações vivenciadas etc.

Os questionários foram enviados por meio de uma plataforma de comunicação virtual (WhatsApp), com a escolha de quatro (04) docentes da Escola São Francisco do Ensino Fundamental II, para que as respostas fossem de abordagens diferentes. Além dos docentes, participaram cinco (05) estudantes no mesmo período para avaliar as práticas pedagógicas dos docentes.

Para preservar as identidades dos integrantes da pesquisa, as respostas dos questionários fizeram-se uso de códigos, em substituição dos nomes dos participantes.

No Quadro 01, está exposto um breve perfil dos(as) entrevistados(as) Professores/as:

Quadro 1- perfil dos(as) entrevistados(as):

$\begin{array}{lllll}\text { NOME FICTICIO } & \text { FUNÇÃ } \boldsymbol{O} & \text { SEXO } & \text { VÍNCULO } & \text { ESCOLARIDADE } \\ \text { Professor, P1 } & \text { Docente } & \text { Masculino } & \text { Concursado } & \text { Mestre } \\ \text { Professor, P2 } & \text { Docente } & \text { Feminino } & \text { Concursado } & \text { Pós-Graduada } \\ \text { Professor, P3 } & \text { Docente } & \text { Feminino } & \text { Concursado } & \text { Mestra } \\ \text { Professor, P4 } & \text { Docente } & \text { Feminino } & \text { Concursado } & \text { Pós-Graduada }\end{array}$

No Quadro 02, está exposto um breve perfil dos(as) entrevistados(as) Alunos/as:

Quadro 1-perfil dos(as) entrevistados(as):

\begin{tabular}{|c|c|c|c|}
\hline NOME FICTICIO & $F U N C ̧ \tilde{A} O$ & SEXO & SÉRIE \\
\hline Aluno, $A 1$ & Estudante & Feminino & $9^{0} \mathrm{ANO}$ \\
\hline Aluno, $A 2$ & Estudante & Feminino & $9^{0} \mathrm{ANO}$ \\
\hline Aluno, A3 & Estudante & Feminino & $9^{0} \mathrm{ANO}$ \\
\hline Aluno, A4 & Estudante & Feminino & $9^{0} \mathrm{ANO}$ \\
\hline Aluno, A5 & Estudante & Feminino & $9^{0} \mathrm{ANO}$ \\
\hline
\end{tabular}

Fonte: elaborados pelos autores (2019).

A sistematização dos dados, de acordo com essas categorias e na correlação com a literatura, permitiu a melhor compreensão sobre as ações e impactos da pandemia no sistema de ensino e nas desigualdades educacionais. Os dados foram organizados de acordo com o quadro acima e este serviu como fio estruturante para a apresentação e discussão dos dados da pesquisa no Ensino Fundamental II da Escola são Francisco.

\section{Resultados e discussões dos dados}

A escola pública, que já se mantinha em condições precárias, passa a ser obrigada a criar estratégias no contexto atual, devido as mudanças ocorridas nos últimos anos. Assim, esta pesquisa buscou problematizar, sob práticas pedagógicas e as perspectivas dos docentes, nas 
quais foram adaptadas e implementadas na Escola São Francisco que concentra na rede municipal de ensino de Serra do Ramalho, principalmente em relação às avaliações e como a gestão escolar tem lidado com essas situações atípicas das transformações e mudanças atuais.

Segundo Luckesi (2007, p.15), “Uma escola é o que são os seus gestores, os seus educadores, os pais dos estudantes, os estudantes e a comunidade. A cara da escola decorre da ação conjunta de todos esses elementos”. Isto é, a escola é administrada em função de sua comunidade e com sua comunidade com participação efetiva de todos. Assim, ela é o espelho de seus gestores.

A gestão democrática é um princípio constitucional fortalecido pela LDBEN (Lei de Diretrizes e Bases da Educação Nacional), Lei n. 9394/96 de 20 de dezembro de 1996, Lei Darcy Ribeiro e distingue-se pela pratica dos seus gestores associados a uma visão de educação emancipadora. Ela exige um gestor capaz de identificar e programar espaços de aprendizagem compatíveis com uma educação participativa, certificando a construção de escolas solidárias, democráticas e competentes.

Segundo o Art. 14, da lei de Diretrizes e Bases da Educação Nacional n. 9394/96, os sistemas de ensino definirão as normas de gestão democrática do ensino público na educação básica, de acordo com suas peculiaridades e conforme os seguintes princípios:

I - participação dos profissionais da educação na elaboração do projeto pedagógico da escola; II - participação das comunidades escolar e local em conselhos escolares ou equivalentes. Art. 15. Os sistemas de ensino assegurarão às unidades escolares públicas de educação básica que os integram progressivos graus de autonomia pedagógica e administrativa e de gestão financeira, observadas as normas gerais de direito financeiro público.

A gestão democrática permite o controle da sociedade civil sobre a educação e a escola pública, introduzindo a eleição de dirigentes escolares e os conselhos escolares, garante a liberdade de expressão, de pensamento, de criação e de organização coletiva da escola, e facilita a luta por condições materiais para aquisição e manutenção dos equipamentos escolares (material didático, de pesquisa e leitura, de informatização), bem como por salários dignos a todos os profissionais da educação (BASTOS 2002: p. 78). O que nos remete à necessidade de se estabelecer a gestão democrática na escola, bem como de se estabelecerem relações de reciprocidade na construção do coletivo.

Em relação a avaliação na Escola São Francisco com os alunos do Ensino Fundamental II, Hoffmann (1996) esclarece: “entendo que a avaliação, enquanto relação dialógica vai conceber o conhecimento como apropriação do saber pelo aluno e pelo professor, como açãoreflexão-ação que se passa na sala de aula em direção a um saber aprimorado, enriquecido, 
carregado de significados, de compreensão.” (P.148) Esta autora esclarece que, o diálogo, entendido a partir dessa relação epistemológica não é obrigatoriamente uma conversa verbalizada entre professor e aluno. Ele é mais amplo e complexo. É uma reflexão em conjunto com o aluno sobre o objeto do conhecimento, para encaminhar-se à superação. Isto significa desenvolver uma relação dialógica, teórico-prática, fundamental na avaliação mediadora.

\section{Questionário com os Docentes}

Quando questionamos aos docentes sobre a formação para uma educação mais inovadora e transformadora e se a unidade escolar junto com a secretaria de educação oferece formação continuada para os docentes? Se sim, como tem ocorrido esse processo? Responderam,

Sim, a gestão ofereceu algumas, pelos coordenadores de área e outra por etapas em jornadas pedagógicas. (PROFESSOR, P1)

\section{Atualmente sim. (PROFESSOR, P2)}

Temos no município uma equipe de coordenadores na secretaria de educação, que também são professores do município, que nos auxiliam com sugestões por área de conhecimento e também a secretaria de educação promove formação continuada e mini cursos. (PROFESSOR, P3)

Sim, a Secretaria de Educação tem oferecido formação continuada aos docentes. (PROFESSOR, P4).

A avaliação na concepção de Both (2007), vem atrelada ao processo, onde se direciona a qualidade do desempenho sobre a quantidade de atividades propostas, tanto para o aluno quanto para o professor, ficando em um processo comparativo. Porém na visão do autor, o foco principal é a qualidade do ensino, ultrapassando os limites da verificação.

Quando questionamos sobre a visão pedagógica que o Professor do Ensino Fundamental II da Escola Municipal São Francisco, tem sobre o processo de avaliar? Responderam:

Na minha opinião a maioria não valoriza todo o contexto quando vai avaliar o aluno e usa mais as notas que tiram nas avaliações que a evolução na aprendizagem do aluno. (PROFESSOR, P1)

Os professores da referida Escola, tem visto a avaliação como uma pratica essencial na atuação de qualquer educador, tendo conhecimento que os tempos mudaram e com isso as formas de avaliação também. (PROFESSOR, P2)

Na minha concepção, avaliar é muito mais do que atribuir notas ao estudante, é acompanhar o desenvolvimento da aprendizagem do educando, bem como, observar o desempenho pedagógico. (PROFESSOR, P3)

Os professores veem a avaliação como um processo contínuo que só se faz sentido quando leva ao desenvolvimento do educando de acordo com Luckesi: Sendo assim, o professor procura avaliar aquilo que foi ensinado 
para depois fazer as intervenções caso necessário, para que o (a) aluno (a) possa adquirir os conhecimentos necessários. (PROFESSOR, P4)

A avaliação educacional serve como um mecanismo de diagnóstico da situação visando o avanço e o crescimento e possibilita ao aluno condições de emancipação humana. (LUCKESI, 2005, p.31). Nesse sentido, sobre a Avaliação aplicada pelo Professor do Ensino Fundamental II da Escola Municipal São Francisco está contribuindo na Aprendizagem do Aluno?

Na maioria dos casos não, pois como já havia dito não se avalia a evolução da aprendizagem visam mais as notas que adquire nas avaliações. (PROFESSOR, P1)

Sim, uma vez que a mesmo serve para diagnosticar a situação de aprendizagem e ao mesmo tempo, verificar o quanto do objeto de conhecimento foi absorvido pelo o educando, bem como aferir se eles estão conseguindo acompanhar os conteúdos. (PROFESSOR, P2)

Os professores são agentes fundamentais no processo ensino-aprendizagem e devem posicionar-se diante da avaliação de aprendizagem. (PROFESSOR, P3)

Em parte, sim, os professores têm se confrontado com algumas dificuldades para ensinar e avaliar durante esse período de pandemia. (PROFESSOR, P4).

Quanto o processo de ensino e aprendizagem na Escola São Francisco, Para Vasconcellos (2005), o processo de conquista de conhecimento de forma dialógica, supera o senso comum deformado a respeito da avaliação, mas para se concretizar uma transformação é preciso envolver todo o coletivo escolar. Como a Escola Municipal São Francisco tem trabalhado junto aos professores a Avaliação como Ferramenta de Construção da Aprendizagem?

Na verdade, não se tem esse trabalho no geral em todas as escolas. O que se tem é, uma cobrança que vem da secretaria de educação, que chega à direção da escola e que a direção repassa para os professores, que tem que dar um jeito de melhorar as notas dos alunos de alguma forma (sem muita preocupação com a aprendizagem em si). (PROFESSOR, P1)

Sim. Pois o mesmo é feito por todos os envolvidos na educação \{alunos, pais, professores e coordenador... \} possibilitando assim, perceber as necessidades nesse processo avaliativo. (PROFESSOR, P2)

A proposta de avaliação da instituição tem como objetivo orientar, comparar, $e$ instigar o aluno a buscar a construção do seu próprio conhecimento. Através do qual, professor e aluno, analisam, com segurança, o desempenho um do outro. (PROFESSOR, P3)

A escola tenta estabelecer um diálogo junto aos professores com o intuito de trabalhar de forma coletiva, com o objetivo de utilizar o processo de avaliação como um meio de tentar como o aluno se encontra naquele momento em que a avaliação ocorre, assim a escola pode estabelecer 
ferramentas adequadas para que possibilite ao aluno efetivar sua aprendizagem. (PROFESSOR, P4)

Gasparin (2005) nos mostra que esse tipo de avaliação não ocorre apenas nessa fase, mas durante o transcorrer de todas as atividades. A catarse é a demonstração teórica do ponto de chegada. Daqui o aluno retorna à prática social, mas manifestando uma nova postura prática, uma nova atitude sobre o conteúdo e uma nova forma de agir.

\section{Questionário com os Estudantes}

Para a realização da pesquisa com os/as estudantes sobre (A avaliação como ferramenta de construção da aprendizagem), os questionários foram enviados para cinco (05) estudantes que estudam no Ensino Fundamental II da unidade escolar São Francisco, apresentando diferentes respostas no questionário. Importante destacar que a escolha dos sujeitos da pesquisa (05 estudantes), se deu mediante a necessidade de chegar as respostas concretas nos questionamentos do decorrer da pesquisa.

Ao questionarmos os alunos sobre o processo de avaliação da aprendizagem com o uso das atividades, se os docentes avaliam o desempenho com responsabilidade e ética, responderam?

- Todos os/as cinco (05) estudantes responderam, sim.

Ao analisarmos sobre a avaliação das notas apresentadas pelos docentes nas atividades, pode apresentar em algum momento erros?

- Todos os/as cinco (05) estudantes responderam, não.

Sabemos das demandas e cargas horárias excessivas dos professores. Nesse sentido, perguntamos aos alunos se acontece dos docentes fazer as correções das avaliações de provas e atividades na sala de aula?

- Sete (03) alunos responderam, sim. Um (01) aluno respondeu: "alguns professores sim, para adiantar o processo". Um (01) aluno respondeu, não.

Ao perguntar os/as cinco (05) estudantes sobre a avaliação se é importante e fundamental para o processo de ensino e aprendizagem? Responderam,

- Todos os/as cinco (05) estudantes responderam, sim.

\section{Projeto Político Pedagógico da Escola São Francisco}

O Projeto Político Pedagógico - PPP, é um documento construído de forma democrática, dialógica e compartilhada pelos membros que compõem a comunidade escolar. Para tanto, esse projeto deve conter elementos que permitam propiciar o resultado esperado na sua aplicação. Sobre esses elementos essenciais do PPP no ambiente escolar, no que remete a 
temática sobre o sistema de avaliação como ferramenta de construção da aprendizagem no Ensino Fundamental II da Escola Municipal São Francisco em Serra do Ramalho - Ba, se faz necessário conhecer numa totalidade de como procedeu os anseios e as realidades dos educadores, as famílias e comunidade geral inseridos nesse espaço para um PPP democrático.

Sobre o PPP (Documento que sustenta a Escola São Francisco), importante salientar que na análise documental, um pesquisador utiliza documentos objetivando buscar informações e usar técnicas apropriadas para o manuseio e análise. Alguns procedimentos são necessários, tais como a organização das informações a serem categorizadas e, posteriormente, analisadas, e a elaboração de sínteses, ou seja, a realidade, as ações dos investigadores - cujos objetos são documentos.

A Escola São Francisco, situada na rua T n ${ }^{\circ} 3.395$, Agrovila 02, Serra do Ramalho -BA. Foi inaugurada dia $1^{\circ}$ de abril de 1977 , sendo aberta com cinco salas, dois sanitários, uma cantina, um almoxarifado, uma sala para professores/as, uma sala para diretoria e um pátio. Funcionando com ensino infantil, ensino fundamental de $1^{\mathrm{a}}$ à $4^{\mathrm{a}}$ série e o Mobral (educação de jovens e adultos).

Com 260 alunos/as, em três turnos. Durante o mesmo ano houve a convocação dos/as moradores/as para escolher o nome da escola, o qual foi registrado por grupo escolar São Francisco, em homenagem ao padroeiro desta comunidade.

Para atender às necessidades da comunidade foi implantada em 1985 o ensino fundamental de $5^{\mathrm{a}}$ a $8^{\mathrm{a}}$ séries, com a extensão da escola Castro Alves da Agrovila 09, deste Município. Em 1997 com a Lei 077/97 de 30 de abril do mesmo ano foi aprovada a independência da escola São Francisco da extensão Castro Alves.

Mais uma vez a escola São Francisco entende sua modalidade de ensino. A partir de 1999, implantou-se o segundo grau com extensão de colégio Castro Alves com os cursos de formação geral Magistério. Entretanto com a nova lei LDB o segundo grau passou a ser responsabilidade estadual e no ano de 2002 a escola teve que extinguiu o curso de magistério e oferece apenas o curso de formação geral noturno. Atualmente a escola atende a educação básica.

Durante toda essa temporada de atividades escolar procurou se trabalhar atividades voltadas para o desenvolvimento cognitivo e social do aluno em consonância com a comunidade. Tendo em vista a nossa prática pedagógica está norteada pela pedagogia libertadora devido à formação superior dos docentes favorecer a essa educação.

A construção do Projeto Político Pedagógico, seu posto como atividade escolar da Rede UNEB-2000, tornou-se um instrumento fundamental no apoio a educação de Serra do Ramalho, 
oferecendo as escolas maior autonomia e abertura para realização de experiências inovadoras. Esse documento é de fundamental importância para orientar o fazer pedagógico, porém sua análise e reavaliação só veio à tona com a provocação da Secretaria de Educação no ano de 2017.

A primeira versão de projeto político pedagógico dessa entidade escolar a partir da iniciativa dos professores e alunos da Rede UNEB 2002, que abre uma discussão sobre a atual situação dessa escola, onde todo o corpo docente está aberto para futuras propostas. Em que no primeiro momento houve na escola um seminário onde discutimos com a comunidade escolar os as seguintes temáticas: avaliação, gestão, democracia, tendências pedagógicas e o projeto político pedagógico. No segundo momento, houve uma reunião com a comunidade escolar e extraescolar (pais, alunos/as, representantes das igrejas, líderes de associação).

Mediante o seminário e reunião, percebemos que os docentes atuantes nas seguintes modalidades de ensino infantil, fundamental e médio, encontram-se em dificuldade de trabalhar interdisciplinarmente e, a metodologia está desconexo contextualizada da realidade do/a aluno/a, leitura decodificada. As relações interpessoais da escola afetadas por falta de comunicação entre o corpo administrativo e os docentes. Falta maior entrosamento da comunidade nas questões escolar, o índice de reprovação nas séries iniciais é significativo, notase a falta de atividades esportivas no ambiente escolar.

Convém lembrar que é de fundamental importância uma reforma Geral ao ambiente escolar como: jornalões nas salas de aula, iluminação (mudança de transformador), banheiros, cozinha, sala para professores, sala de áudio e vídeo, construção do muro e uma quadra poliesportiva. Discutimos ainda necessidade de uma horta escolar e uma biblioteca para melhor atender a demanda da comunidade escolar e extraescolar.

Na tentativa de alcançar essas metas percebemos que o PPP é a mola do dinamismo se tornando um instrumento de ação, transformação o qual levará o/a educador/a refletir sobre um trabalho voltado para a inclusão social, abolindo todas as formas, de preconceito social, portanto a interdisciplinaridade é um fator primordial para um ensino de qualidade.

Na práxis revolucionária da Escola São Francisco, há uma unidade dialógica entre direção, docentes e discentes no processo de libertação e a revolução é vista como caminho para a superação da contradição. Ação e reflexão devem ser simultâneas. Assim, “[...] o diálogo tem significação precisamente porque os sujeitos dialógicos não apenas conservam, mas a defendem e assim crescem um com o outro [...]" (FREIRE, 1993, p.118). Jamais se deve esperar, ingenuamente, das elites, uma educação de caráter libertário, pois a revolução é 
pedagógica e "[...] por isso é que o caminho da revolução é o da abertura às massas populares, não fechamento a elas" (FREIRE, 2005, p.156).

\section{Considerações finais}

Diante do contexto atual, os desafios assumidos pela direção, docentes e alunos da Escola São Francisco, que faz parte da rede de ensino de educação de Serra do Ramalho, Bahia, evidenciam as grandes dificuldades em aderir processo de ensino/aprendizado nesse período de transformações e mudanças tecnológicas. Aja visto que os educadores não estão tendo formação continuada para adaptação das novas formas de construção do conhecimento.

Quanto aos dados coletados na pesquisa, se centralizaram por questionários aplicados por meio de uma plataforma de comunicação virtual (WhatsApp), com a escolha de quatro (04) docentes da Escola São Francisco do Ensino Fundamental II, para que as respostas fossem de abordagens diferentes. Além dos docentes, participaram cinco (05) estudantes no mesmo período para avaliar as práticas pedagógicas na unidade escolar. Também foi feito o tratamento do PPP da escola São Francisco, no sentido de avaliar as concepções e atuações dos docentes e o corpo pedagógico.

Percebeu-se que a avaliação vem sendo um tema muito discutido e polêmico entre educadores, e muitas vezes esquecido o seu real significado. Revelou-se como um instrumento valioso no processo ensino aprendizagem, podendo ser uma via de mão dupla, possibilitando um possível diagnóstico do aluno sobre os conhecimentos adquiridos em um período. Para o professor propiciou verificar e refletir a sua prática pedagógica constantemente no ato de auto avaliar-se, podendo assim haver uma melhoria no processo de ensino e aprendizagem.

Esta pesquisa ainda evidenciou como o trabalho coletivo na unidade escolar São Francisco proporcionou o maior entendimento da importância do projeto político pedagógico na gestão democrática e na função social da escola, buscando uma participação coletiva e efetiva da comunidade para o alcance dos objetivos inseridos no projeto. Percebeu-se também que várias dificuldades precisam ser vencidas como a resistência à participação dos pais e demais representantes da comunidade escolar, a falta de politização e o comodismo.

A avaliação como verificação é limitada por apenas coletar informações sobre o que o aluno conseguiu resolver na prova, sem rever as possibilidades para a aprendizagem de conteúdos não assimilados, portanto, não considera alguns aspectos que podem interferir nos resultados dessa verificação, tornando-se somente uma medida para a classificação e que ainda continua sendo o método mais praticado.

\section{Referências}


BASTOS, João Batista (org.). Gestão democrática. Rio de Janeiro: SEPE, 2002.

BOTH, Ivo José. Avaliação planejada, aprendizagem consentida: a filosofia do conhecimento. $1^{\text {a }}$ Edição, Curitiba, PR: IBPEX, 2007.

BRASIL. Constituição (1988). Constituição da República Federativa do Brasil: promulgada em 5 de outubro de 1988. Brasília, 1998.

BRASIL. Lei no 9.394, de 20 de dezembro de 1996. Estabelece as diretrizes e bases da Educação Nacional. Brasília, 1996.

ESCOLA SÃO FRANCISCO. Projeto Político Pedagógico - PPP.

FOUCAULT, Michel. Vigiar e punir: nascimento da prisão. Tradução Raquel Ramalhete. 36. ed. Petrópolis: Vozes, 2009.

FREIRE, Paulo. Política e educação. São Paulo: Cortez, 1993.

FREIRE, Paulo. Pedagogia do oprimido. 45. ed. Rio de Janeiro: Paz e Terra, 2005.

GASPARIN, João Luiz. Uma didática para a pedagogia histórico-crítica. 3.ed. Campinas, SP: Autores Associados, 2005.

GIL, Antônio. Métodos e técnicas de pesquisa social. São Paulo: Atlas, 1999.

HOFFMANN, Jussara. Avaliação Mediadora. Porto Alegre: Editora Mediação, 1996.

KOSIK, Karel. Dialética do concreto. Rio de Janeiro: Paz e Terra, 1976.

KRAEMER, Maria. Avaliação da aprendizagem como construção do saber. 2006.

LUCKESI, Cipriano Carlos. Avaliação da aprendizagem escolar: estudos e proposições. 17. Ed. São Paulo: Cortez, 2005.

LUCKESI, Carlos Cipriano. Gestão Democrática da escola, ética e sala de aula. ABC Educatio, n. 64. São Paulo: Criarp, 2007.

VASCONCELLOS, Celso. Avaliação: concepção dialética libertadora do processo de avaliação escolar. 15. Ed. São Paulo: Libertad, 2005. 